University of Wollongong

Research Online

Australian Institute for Innovative Materials -

Papers

Australian Institute for Innovative Materials

$1-1-2018$

Investigation on the Catalytic Performance of

Reduced-Graphene-Oxide-Interpolated FeS2 and FeS for Oxygen Reduction Reaction

\author{
Hengyi Fang \\ University of Jinan \\ Taizhong Huang \\ University of Jinan \\ Jianfeng Mao \\ University of Wollongong, jmao@uow.edu.au \\ Shuo Yao \\ University of Jinan \\ M Dinesh \\ University of Jinan
}

See next page for additional authors

Follow this and additional works at: https://ro.uow.edu.au/aiimpapers

Part of the Engineering Commons, and the Physical Sciences and Mathematics Commons

Research Online is the open access institutional repository for the University of Wollongong. For further information contact the UOW Library: research-pubs@uow.edu.au 


\title{
Investigation on the Catalytic Performance of Reduced-Graphene-Oxide-Interpolated FeS2 and FeS for Oxygen Reduction Reaction
}

\author{
Abstract \\ The oxygen reduction reaction (ORR) plays a key role in many kinds of energy conversion and energy \\ storage devices, especially in fuel cells. Developing low-cost, easily prepared, and high-efficiency catalysts \\ is a crucial factor for the large-scale applications of fuel cells. Herein, we report the reduced graphene \\ oxide ( $\mathrm{rGO}$ ) interpolated FeS2and FeS as low cost and high performance electrocatalyst for ORR in the \\ alkaline electrolyte. Cyclic voltammetry tests indicate that the onset potential of the ORR for FeS2@rGO is \\ $-0.142 \mathrm{~V}$, which is close to the state-of-the-art commercial Pt/C $(-0.114 \mathrm{~V})$ catalyst. A low Tafel slope of \\ $98 \mathrm{mV} /$ decade and high durability are also observed for the FeS2@rGO composite for ORR. The reaction \\ kinetics study shows that the rGO-interpolated FeS2catalyzed ORR major happen through 4-electron \\ pathway, but the rGO-interpolated FeS catalyzed ORR major happen through mixed 2-electron and \\ 4-electron pathway. The S-S bond of FeS2play the major role for the happening of ORR through 4-electron \\ pathway. \\ Keywords \\ reduction, oxygen, fes, fes 2 , reduced-graphene-oxide-interpolated, catalytic, performance, investigation, \\ reaction \\ Disciplines \\ Engineering | Physical Sciences and Mathematics

\section{Publication Details} \\ Fang, H., Huang, T., Mao, J., Yao, S., Dinesh, M. Mayilvel., Sun, Y., Liang, D., Qi, L., Yu, J. \& Jiang, Z. (2018). \\ Investigation on the Catalytic Performance of Reduced-Graphene-Oxide-Interpolated FeS2 and FeS for \\ Oxygen Reduction Reaction. ChemistrySelect, 3 (37), 10418-10427.
}

\section{Authors}

Hengyi Fang, Taizhong Huang, Jianfeng Mao, Shuo Yao, M Dinesh, Yue Sun, Dong Liang, Lei Qi, Jiemei Yu, and Zhankun Jiang 


\title{
Investigation on the Catalytic Performance of Reduced Graphene Oxide Interpolated $\mathrm{FeS}_{2}$ and $\mathrm{FeS}$ for Oxygen Reduction Reaction
}

\author{
Hengyi Fang, ${ }^{[a]}$ Taizhong Huang, ${ }^{\text {[a] }}$ Jianfeng Mao, ${ }^{*[b]}$ Shuo Yao, ${ }^{[a]}$ M. Mayilvel Dinesh, ${ }^{[a]}$ Yue Sun, ${ }^{[a]}$ \\ Dong Liang, ${ }^{[a]}$ Lei Qi, ${ }^{[a]}$ Jiemei $Y u,{ }^{[a]}$ and Zhankun Jiang ${ }^{[a]}$
}

\begin{abstract}
The oxygen reduction reaction (ORR) plays a key role in many kinds of energy conversion and energy storage devices, especially in fuel cells. Developing low-cost, easily prepared, and high-efficiency catalysts is a crucial factor for the large-scale applications of fuel cells. Herein, we report the reduced graphene oxide (rGO) interpolated $\mathrm{FeS}_{2}$ and $\mathrm{FeS}$ as low cost and high performance electrocatalyst for ORR in the alkaline electrolyte. Cyclic voltammetry tests indicate that the onset potential of the ORR for $\mathrm{FeS}_{2} @ \mathrm{rGO}$ is $-0.142 \mathrm{~V}$, which is close to the state-of-the-art commercial $\mathrm{Pt} / \mathrm{C}(-0.114 \mathrm{~V})$ catalyst. A low Tafel slope of $\sim 98$ $\mathrm{mV} /$ decade and high durability are also observed for the FeS ${ }_{2} @ r G O$ composite for ORR. The reaction kinetics study shows that the rGOinterpolated $\mathrm{FeS}_{2}$ catalyzed ORR major happen through 4-electron pathway, but the rGO-interpolated FeS catalyzed ORR major happen through mixed 2-electron and 4-electron pathway. The S-S bond of $\mathrm{FeS}_{2}$ play the major role for the happening of ORR through 4-electron pathway.
\end{abstract}

\section{Introduction}

Owing to the increasing energy crisis and environmental pollution that resulted from the heavy consumption of fossil fuels, clean energy resources such as wind and solar are playing more and more important roles in the energy field. ${ }^{[1]}$ In order to adopt these intermittent renewable energies efficiently, technologies have been developed to meet the demands of energy conversion and storage..$^{[2]}$ Hence, there is significant interest in electrochemical energy conversion and storage technologies such as fuel cells, batteries, and supercapacitors. Among these devices, fuel cells are of particular interest due to their benefits of high energy intensity, rapid start-up, zero emissions, environmental friendliness, low operating temperature, etc. ${ }^{[3]}$ In general, fuel cell devices generate electricity through electrochemical energy conversion between the anode (hydrogen, methanol, ethanol, etc.) and the cathode (air/oxygen from the atmosphere), where the ions move between the anode and cathode through the electrolyte; whereas the electrons

[a] Hengyi Fang, Prof. Taizhong Huang, Shuo Yao, Dr. M. Mayilvel Dinesh, Yue Sun, Dong Liang, Dr. Lei Qi, Dr. Jiemei Yu, and Dr. Zhankun Jiang Shandong Provincial Key Laboratory of Fluorine Chemistry and Chemical Materials, School of Chemistry and Chemical Engineering University of Jinan Jinan 250022, P.R. China

E-mail: chm huangtz@ujn.edu.cn

[b] Dr. Jianfeng Mao Institute for Superconducting \& Electronic liberated from the anode reach the cathode through the external circuit. $^{[4] \quad A}$ major limiting

sluggish reaction kinetics of the oxygen reduction reaction (ORR) at the cathode, which is determined by the performance of the catalysts on the electrode. ${ }^{[5]}$

Although the platinum $(\mathrm{Pt})$ based catalysts are the most popular ORR catalysts at present, the shortcomings of high cost, easily poisoned, and sluggish activity have become obstacles on the large-scale applications of fuel cells. ${ }^{[6]}$ Therefore, developing high-performance and low-cost electrocatalysts for ORR is the key factor for promoting the wide applications of fuel cells. ${ }^{[7]}$

Recent studies have shown that the integration of electrocatalyst with conducting support such as carbon nanomaterials, is an effective way to developing catalysts with both high catalytic performance and long-time running stability. ${ }^{[8]}$ The combination of the transition metal-based catalyst with conductive nanocarbons represents a promising strategy to improve the overall catalytic performance towards ORR. ${ }^{[9]}$ Compared to the traditional carbon-based materials (carbon nanotubes, carbon black), graphene has special catalytic characteristics for the ORR. ${ }^{[10]}$ Firstly, the graphene, as support for the catalyst, has a strong affinity with other catalysts. Secondly, the graphene also shows some extent catalytic performance towards ORR, which could make it more effective in the catalytic process. ${ }^{[11]}$ The peak current intensity of some grapheneinterpolated transition metal based catalysts for ORR even surpass that of commercial $\mathrm{Pt} / \mathrm{C}$ catalyst. ${ }^{[12]}$ Kinds of transition metal-based catalysts for ORR such as metal oxides, carbides, nitrides, and chalcogenides have been reported. ${ }^{[13]}$ The favorable performance can be attributed to the incomplete outermost $d$ orbital electrons of the transition metal atoms. Among the transition metal elements, the first-row transition metal chalcogenides (e.g. V, Ti, $\mathrm{Fe}$ ) have emerged as high promising catalysts for ORR owning to their advantages of abundant sources, low cost, and considerable activity. ${ }^{[14]}$ The catalytic performance of transition metal based catalysts for ORR can be improved by constructing novel structure and high catalytic active sites, which enhance the efficiency of mass transfer. The catalytic performance of metal sulfides has been reported. But the difficulty of the synthesis of transition metal sulfides with high purity has inhibited their applications as catalysts for ORR. ${ }^{[15,16]}$

In this work, we synthesized $\mathrm{FeS}_{2}, \mathrm{FeS}$, and their nanocomposites with interpolated reduced graphene oxide (rGO), that is, FeS $2_{2} @ r G O$ and FeS@rGO, with high purity, and investigated their catalytic performances for ORR in alkaline electrolyte. It was found that the rGO interpolated $\mathrm{FeS}_{2}$ and $\mathrm{FeS}$ exhibit superior catalytic activity for ORR. Among all the catalysts, $\mathrm{FeS}_{2} @ \mathrm{rGO}$ shows the highest catalytic performance for ORR. To the best of our knowledge, there are scarce report on the rGO interpolated $\mathrm{FeS}_{2}$ as catalyst for ORR in alkaline electrolyte. $\mathrm{FeS}_{2} @ \mathrm{rGO}$ shows better stability than the benchmark Pt/C catalysts for ORR. FeS ${ }_{2} @ r G O$ has great 

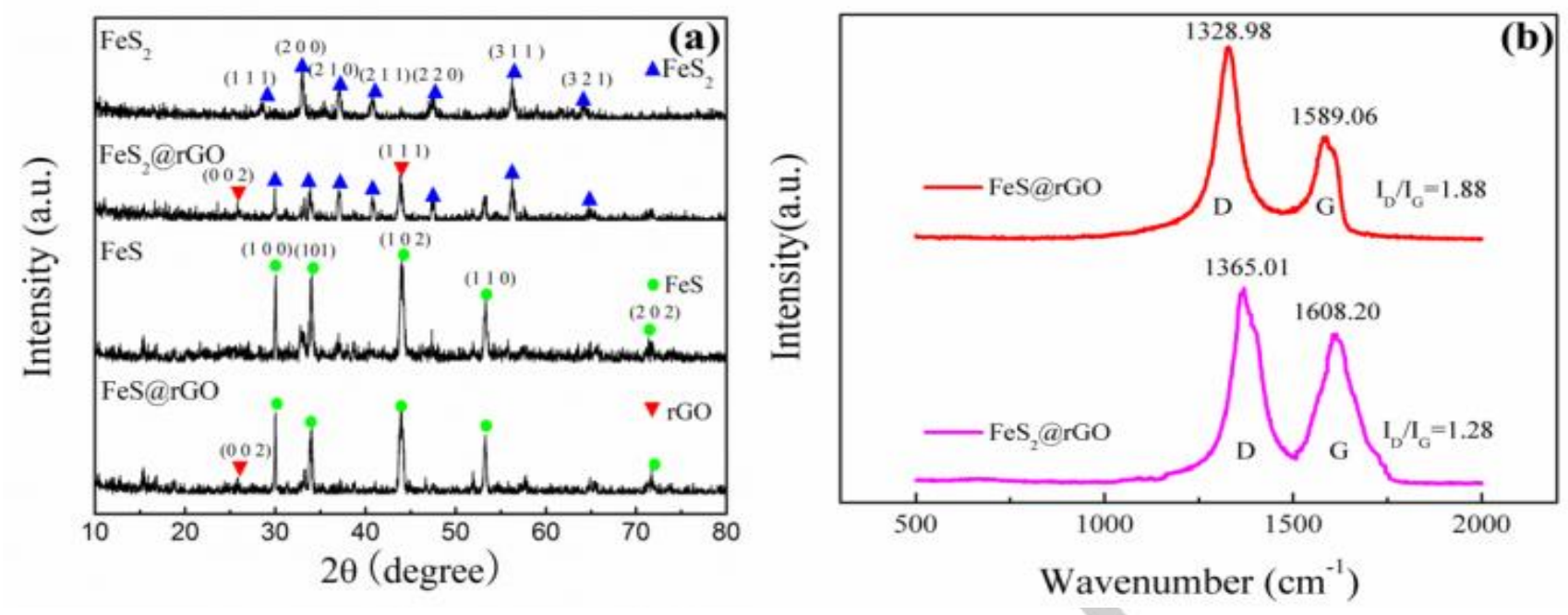

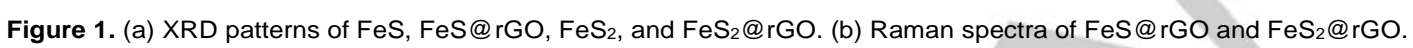

potential to be high performance catalyst for the ORR in cathodes of alkaline fuel cells.

\section{Results and Discussion}

\section{Structural Properties of FeS, FeS@rGo, FeS 2 , and FeS $2 @$ @Go}

The synthesis procedure of FeS, FeS@rGO, FeS 2 and $\mathrm{FeS}_{2} @ \mathrm{rGO}$ are illustrated in Figure S1. The XRD patterns of the synthesized FeS, FeS@rGO, FeS 2 , and FeS ${ }_{2} @ r G O$ are shown in Figure 1a. FeS was easily indexed in both FeS and FeS@rGO, and the corresponding Joint Committee on Powder Diffraction Standards (JCPDS) file number is 659124. The indexed results indicate that the FeS has a primitive hexagonal structure. The calculated cell parameters $a$ and $c$ of $\mathrm{FeS}$ are 0.345 and $0.569 \mathrm{~nm}$, respectively. Similarly, $\mathrm{FeS}_{2}$ is indexed in both $\mathrm{FeS}_{2}$ and $\mathrm{FeS}_{2} @ \mathrm{rGO}$, and the corresponding JCPDS file number is 65-3321, which indicates that the $\mathrm{FeS}_{2}$ has a face-centered cubic (FCC) structure. The calculated cell parameter $a$ of $\mathrm{FeS}_{2}$ is 0.542 $\mathrm{nm}$. The diffraction peak around $27.2^{\circ}$, which is obtained both in FeS $\mathrm{F}_{2} @ \mathrm{rGO}$ and FeS@rGO, could be attributed to the rGO (002) planes. ${ }^{[17]}$

The presence of rGO in FeS@rGO and FeS $2 @ r G O$ was further confirmed by Raman spectroscopy, as shown in Figure 1b. The typical $D$ and $G$ peaks are clearly found in the Raman spectra of both FeS@rGO and $\mathrm{FeS}_{2} @ r G O$, which prove the presence of rGO. Interestingly, the obtained $D$ and $\mathrm{G}$ peaks of FeS@rGO are centered at $1328.98 \mathrm{~cm}^{-1}$ and $1589.06 \mathrm{~cm}^{-1}$, respectively, but for $\mathrm{FeS}_{2} @ \mathrm{rGO}$, the obtained $D$ and $G$ peaks are centered at $1365.01 \mathrm{~cm}^{-1}$ and 1608.20 $\mathrm{cm}^{-1}$. The changes of the corresponding wavenumbers of the $\mathrm{D}$ and $\mathrm{G}$ peaks between FeS@rGO and FeS ${ }_{2} @ r G O$ should be induced by the FeS and FeS 2 . The intensity ratios of $D$ to G peaks, ID/IG, of FeS@rGO and FeS $\mathrm{I}_{2} @ r G O$ are 1.88 and 1.28 , respectively, which means that there are fewer defects in the rGO of FeS $@$ @GO than that of FeS@rGO.[18] The low $I_{D} / I_{G}$ of $F_{e S} @ r G O$ should be attributed to the annealing treatment, which inhibits the occurrence of structural defects. $^{[19]}$

XPS measurements were carried out to examine the elemental compositions and atomic bonding states of $\mathrm{FeS}$, $\mathrm{FeS}_{2}$, and their interaction with $\mathrm{rGO}$. The full spectra of FeS, $\mathrm{FeS}_{2}$,FeS@rGO, and $\mathrm{FeS}_{2} @ r G O$ distinctly reveal the presence of $\mathrm{Fe}$ and $\mathrm{S}$ in the desired stoichiometric ratio (Figures S2-S5). The high-resolution XPS of $\mathrm{Fe}$ and $\mathrm{S}$ of FeS@rGO and FeS ${ }_{2} @ r G O$ have been deconvoluted, and the results are shown in Figure $2 \mathrm{a}$ and $2 \mathrm{c}$. Figure 2a shows that the $\mathrm{Fe} 2 \mathrm{p}_{3 / 2}$ and $\mathrm{Fe} 2 \mathrm{p}_{1 / 2}$ peaks of Fe of $\mathrm{FeS}_{2} @ \mathrm{rGO}$ at 709.5 and $722.8 \mathrm{eV}$, respectively. Figure $2 \mathrm{~b}$ shows that the XPS of S 2p of Fe of FeS@rGO.The two peaks with centered at 161.3 and $162.5 \mathrm{eV}$ should be assigned to $S 2 p_{3 / 2}$ and $S$ $2 \mathrm{p}_{1 / 2}$, respectively. For $\mathrm{FeS}_{2} @ \mathrm{rGO}$ (Figure 2c), the binding energies for $\mathrm{Fe} 2 \mathrm{p}_{3 / 2}$ and $\mathrm{Fe} 2 \mathrm{p}_{1 / 2}$ are centered at 708.6 and $721.3 \mathrm{eV}$, respectively. The binding energies of $\mathrm{Fe} 2 p$ of FeS@rGO and FeS ${ }_{2} @ r G O$ only show small differences. The binding energy of Fe 2p peaks of FeS@rGO and FeS ${ }_{2} @ r G O$ shifted to higher binding energy direction compared to the pristine $\mathrm{FeS}$ or $\mathrm{FeS}_{2}$, which should be attributed to the migration of metal electrons that induced by the strong electronegativity of $O$ species on the $r G O$ surface. The intimate interaction between $\mathrm{rGO}$ and metal sulfides renders the catalysts high conductivity and electrochemical activity. Figure $2 \mathrm{~d}$ shows the XPS of S 2p of $\mathrm{FeS}_{2} @ r G O$. The two strong peaks at 163.9 and $165.1 \mathrm{eV}$ are corresponding to the $S 2 p_{3 / 2}$ and $S 2 p_{1 / 2}$ peaks, respectively. Comparison of the $S$ $2 \mathrm{p}$ peaks of $\mathrm{FeS}$ and $\mathrm{FeS}_{2}$ shows that the binding energy of $\mathrm{S}-\mathrm{Fe}$ bond of $\mathrm{FeS}_{2}$ is stronger than that of $\mathrm{FeS}$, which is the most obvious feature to distinguish these two catalysts. ${ }^{[20]}$ The two small peaks corresponding to the binding energy of 170.0 and $171.3 \mathrm{eV}$ of Figure $2 \mathrm{~d}$ should be attributed to -C$\mathrm{SO}_{x}-\mathrm{C}$ bonds. ${ }^{[21]}$ The XPS test results demonstrate the successful synthesis of $\mathrm{FeS}, \mathrm{FeS}_{2}, \mathrm{FeS} @ \mathrm{rGO}$ and $\mathrm{FeS}_{2} @ r G O$.

Typical SEM images and low resolution TEM images of FeS@rGO and FeS ${ }_{2} @ r G O$ are shown in Figure 3. The SEM 
images of FeS@rGO show regular hexagonal sheets (FeS) which are enveloped by the rGO (Figure 3a). ${ }^{[22]}$
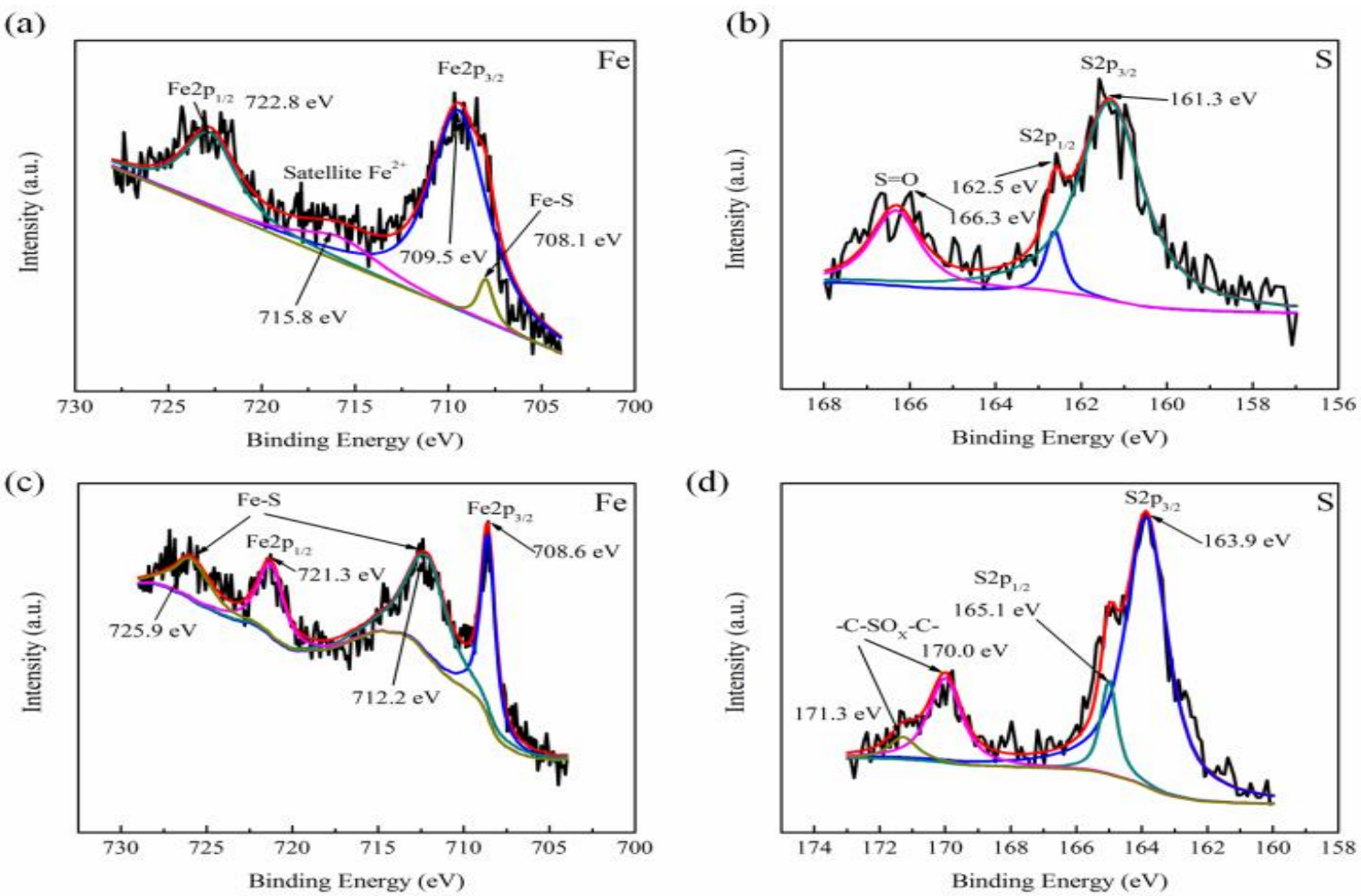

Figure 2. High-resolution XPS of Fe in FeS@rGO (a) and FeS ${ }_{2} @ r G O$ (c); High-resolution XPS of S in FeS@rGo (b) and FeS $@$ rGO (d).

The hexagonal shape of FeS is consistent with the SEM test results (Figure S6a, Supporting Information). Compared with the sheet-like FeS, FeS ${ }_{2} @ r G O$ in Figure $3 b$ and pristine $\mathrm{FeS}_{2}$ in Figure S6b show an octahedral structure.

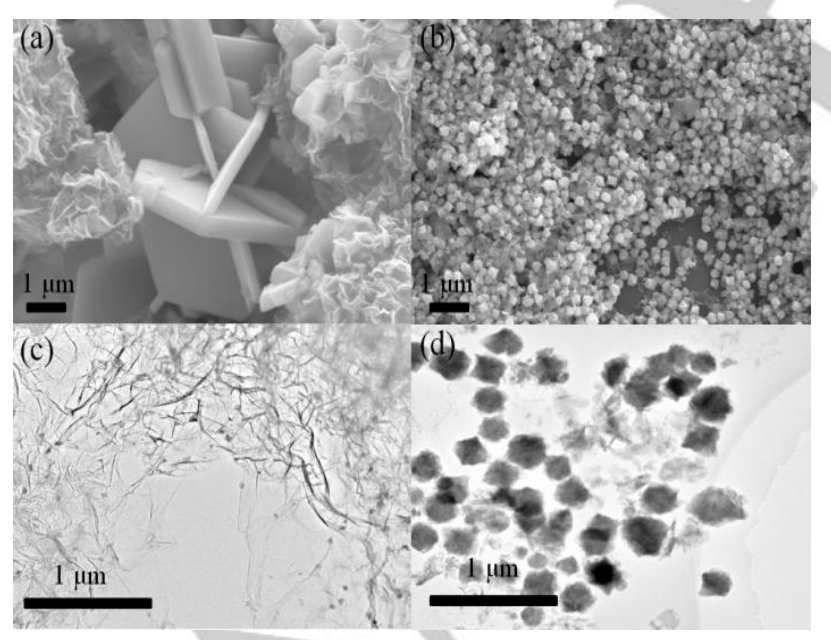

Figure 3. SEM images of FeS@rGO nanosheets (a) and FeS $2 @ r G O$ nanoparticles (b), low- resolution TEM images of FeS@rGO (c) and $\mathrm{FeS}_{2} @ r G O(d)$.

The TEM image in Figure $3 \mathrm{c}$ shows that the FeS nanosheets are evenly distributed on the rGO sheets, which is consistent with the SEM image (Figure 3a). Figure $3 d$ shows that the $\mathrm{FeS}_{2}$ particles are also distributed on the rGO sheets. Compared with the pristine $\mathrm{FeS}_{2}$ (Figure S6d), the size distributions of $\mathrm{FeS}_{2}$ in $\mathrm{FeS}_{2} @ r G O$ is more uniform. Based on the SEM results, the obtained element mappings

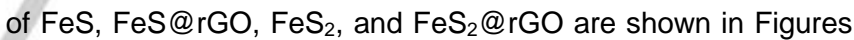
S7-S10 (Supporting Information). The elemental mapping of each catalyst shows the signal of compositional elements. And the distributions of all the elements are consistent with each other, which prove the successful synthesis of each catalyst. 

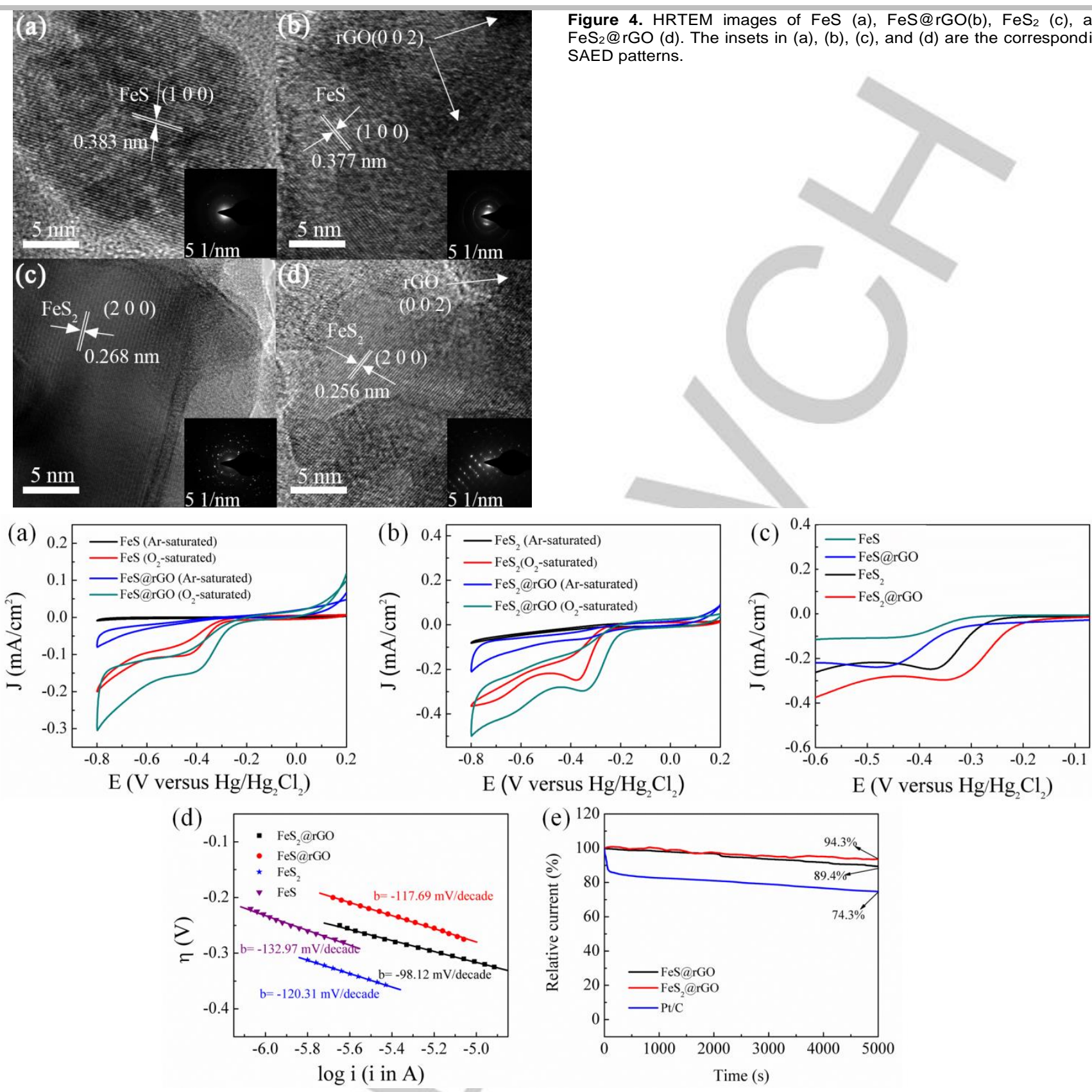

Figure 5. CV tests of FeS and FeS@rGO (a), FeS 2 and FeS $@$ @GO (b) in both oxygen and argon saturated electrolyte, respectively; LSV tests (c) and Tafel (d) tests of FeS, FeS@rGO, FeS 2 and FeS $2 @ r G O ;(e)$ The chronoamperometric tests of FeS@rGO, FeS $2 @ r G O$, and Pt/C catalysts.

The HRTEM image of FeS in Figure $4 a$ clearly shows that the crystal lattice spacing is $0.383 \mathrm{~nm}$, which is corresponding to the (100) facet of FeS. Figure $4 \mathrm{~b}$ shows the HRTEM image of FeS@rGO. (100) facet of FeS with the lattice spacing of $0.377 \mathrm{~nm}$ is also detected. On the other hand, the (002) facet of rGO is also detected in Figure 4b, which illustrates the successful synthesis of FeS@rGO. The SAED patterns of FeS and FeS@rGO are quite similar, which proves the presence of $\mathrm{FeS}$ in both of them. Figure 4c and $4 d$ show the HRTEM images of $\mathrm{FeS}_{2}$ and FeS $\mathrm{F}_{2} @ \mathrm{rGO}$, respectively. The (200) facet of $\mathrm{FeS}_{2}$ are detected in both of them. On the other hand, the SAED patterns of both catalysts
Figure 4. HRTEM images of FeS (a), FeS@rGO(b), FeS 2 (c), and $\mathrm{FeS}_{2} @ r G O(d)$. The insets in (a), (b), (c), and (d) are the corresponding SAED patterns. 
peaks could be detected in the argon saturated electrolyte, which means that all the catalysts can remain stable in the electrolyte during the test process. In contrast, obvious peaks are distinctly detected in the $\mathrm{CV}$ curves of the oxygen saturated electrolyte, which means that the oxygen could be reduced by all the catalysts. Based on the $C V$ tests, the onset potential $\left(E_{\text {onset }}\right)$, peak current potential $\left(E_{\mathrm{p}}\right)$ and peak current intensity $\left(J_{p}\right)$ of the oxygen reduction reaction are obtained, and the results are shown in Table 1.

Table 1 The $E_{\text {onset, }} E_{p}$, and $J_{p}$ of FeS, FeS@rGO, FeS 2 , FeS $2 @$ @rGO, and $\mathrm{Pt} / \mathrm{C}$ catalysts

It is clearly observed that, compared with other catalysts, the onset potential and peak current potential of FeS $\mathrm{F}_{2} @ \mathrm{rGO}$ exhibit a huge shift to the positive direction compared with other catalysts. On the other hand, the FeS ${ }_{2} @ r G O$ catalyzed ORR also shows the highest peak current intensity in all the catalysts. The onset potential of FeS ${ }_{2} @ r G O$ is $-0.142 \mathrm{~V}$, which is just $0.028 \mathrm{~V}$ lower than that of the $\mathrm{Pt} / \mathrm{C}$ catalyst. ${ }^{[24]}$ The FeS $\mathrm{S}_{2} @ \mathrm{rGO}$ shows the highest catalytic activity for ORR, which is further confirmed by the LSV tests (Figure 5c).

Figure 5c shows the LSV tests of FeS, FeS@rGO, FeS 2 , and $\mathrm{FeS}_{2} @ r G O$. It is clearly observed that the results are consistent with the $\mathrm{CV}$ test results. Compared with the pristine $\mathrm{FeS}$ or $\mathrm{FeS}_{2}$, the rGO interpolated catalysts exhibit higher onset potential and higher peak current intensity, which should be attributed to the enhanced conductivity and synergistic effect of $\mathrm{rGO}^{[25]}$ In particular, the catalytic performance for the ORR of FeS ${ }_{2} @ r G O$ hybrid is close to that of super $\mathrm{Pt} / \mathrm{C}$ catalyst in terms of the onset potential and the peak current intensity. ${ }^{[26]}$

The superior ORR catalytic activity of $\mathrm{FeS}_{2} @ r G O$ is also confirmed by its low Tafel slope as shown in Figure $5 \mathrm{~d}$. The Tafel slopes of FeS, FeS@rGO, FeS 2 , and FeS $@$ rGO are 132.97, 117.69, 120.31 and $98.12 \mathrm{mV} \cdot$ decade $^{-1}$, respectively The Tafel slope of FeS ${ }_{2} @ r G O$ is even lower than that of Pt/C catalyst (119 mV·decade $\left.{ }^{-1}\right) \cdot{ }^{[27]} \mathrm{FeS}_{2} @ \mathrm{rGO}$ has the lowest polarization potential among the four catalysts, which is benefit to the continuous long-time running stability. Based on the Tafel tests, the exchange current intensity and electron transfer coefficient of ORR with the catalysts could be calculated according to Tafel's equation (1):[28]

$$
\eta=a+b \log i=-\frac{2.303 R T}{\alpha n F} \log i_{0}+\frac{2.303 R T}{\alpha n F} \log i
$$

Where $\eta$ is the overpotential, $a$ is the intercept of the Tafel plot, $b$ is the Tafel slope, $R$ is the universal gas constant $(8.314 \mathrm{~J} /(\mathrm{mol} \cdot \mathrm{K})), T$ is the temperature in $\mathrm{K}, F$ is the Faraday constant $96485 \mathrm{C} / \mathrm{mol}, n$ is the reaction electron number, $\alpha$ is the electron transfer coefficient, and $i_{0}$ is the exchange current intensity on the catalyst surface. The calculated $a$ and $i_{0}$ are shown in Table 2. Clearly, the FeS ${ }_{2} @ r G O$ shows the highst electron transfer coefficient and exchange current intensity, which also confirms that the electrocatalytic activity of $\mathrm{FeS}_{2} @ r G O$ is the highest among the four catalysts.
The long-time running stability of the catalysts is investigated by the current-time chronoamperometric tests, and the results are shown in Figure $5 \mathrm{e}$. The results show that, apart from high catalytic activity, the FeS $\mathrm{F}_{2} @ r G O$ catalyst also exhibits the highest catalytic durability. After a continuous 5000 s running, the current intensity of $\mathrm{FeS}_{2} @ r G O$ is still remained above $94.3 \%$, which is significantly higher than that of the benchmark Pt/C (74.3\%), and the FeS@rGO (89.4\%). As comparison, the current-time chronoamperometric test results for $\mathrm{FeS}$ and $\mathrm{FeS}_{2}$ are shown in Figure S11, which also demonstrates that the relative current intensity can be kept

\begin{tabular}{|c|c|c|c|}
\hline Catalyst & $E_{\text {onset }}(\mathrm{V})$ & $E_{p}(\mathrm{~V})$ & $J_{p}\left(\mathrm{~mA} \mathrm{~cm} \mathrm{~cm}^{-2}\right)$ \\
\hline $\mathrm{FeS}$ & -0.284 & - & 0.103 \\
\hline Fes@rGO & -0.249 & 0.455 & 0.146 \\
\hline $\mathrm{FeS}_{2}$ & -0.208 & - & 0.251 \\
\hline & & 0.351 & \\
\hline $\mathrm{FeS}_{2} @ \mathrm{rGO}$ & -0.142 & - & 0.332 \\
\hline $\mathrm{Pt} / \mathrm{C}$ & -0.114 & $\begin{array}{l}- \\
0.269\end{array}$ & 0.440 \\
\hline
\end{tabular}

at $92.4 \%$ and $94.4 \%$. The differences in the long-term running stability of these four catalysts should be attributed to their intrinsic structure characteristics and the influence of the interpolated rGO.

The electrocatalytic activity and electron kinetics for ORR of the FeS@rGO and FeS $\mathrm{F}_{2} @ r G O$ catalysts were also investigated by using rotating disk electrode (RDE) tests. The RDE tests of FeS@rGO and FeS ${ }_{2} @ r G O$ are shown in Figure 6, respectively, while the RDE tests for FeS andFeS are supplied in Figure S12. It is distinctly observed that, to each catalyst, the current intensity of ORR increases with the increase of rotating speed at the same potential, which should be attributed to the enhanced oxygen diffusion on the electrode. ${ }^{[29]}$ It can also be seen from the results that the current intensity of FeS@rGO and FeS ${ }_{2} @ r G O$ are higher than of pristine $\mathrm{FeS}$ and $\mathrm{FeS}_{2}$.

Table 2 Tafel slope, electron transfer coefficient and exchange current intensity of the FeS, FeS@rGO, FeS 2 , and FeS $2 @ r G O$ for ORR.

\begin{tabular}{lccc} 
Catalyst & $b\left(\mathrm{mV} \mathrm{dec}^{-}\right.$ & $\alpha$ & $i_{0}\left(\mathrm{~mA} \mathrm{~cm}^{-2}\right)$ \\
\hline FeS & 132.97 & 0.21 & $1.8 \times 10^{-8}$ \\
FeS@rGO & 117.69 & 0.28 & $3 \times 10^{-8}$ \\
$\mathrm{FeS}_{2}$ & 120.31 & 0.24 & $4.1 \times 10^{-8}$ \\
$\mathrm{FeS}_{2} @ \mathrm{rGO}$ & 98.12 & 0.34 & $6.2 \times 10^{-8}$
\end{tabular}




\section{ARTICLE}

(a)

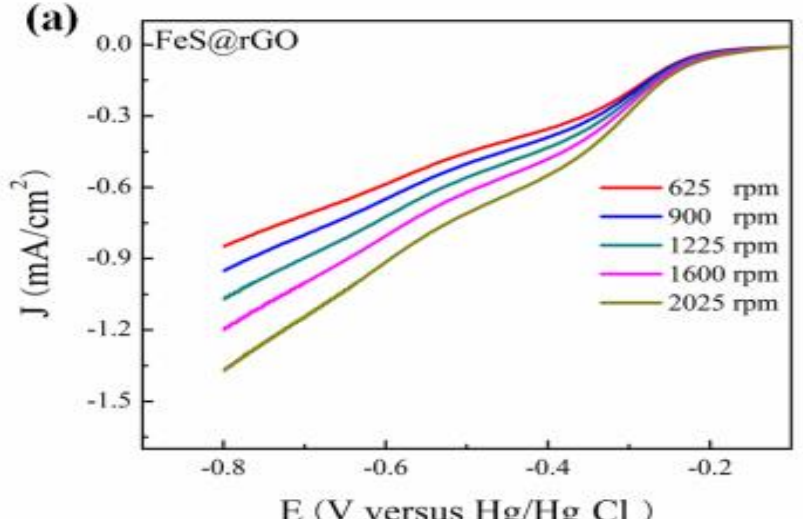

(c)

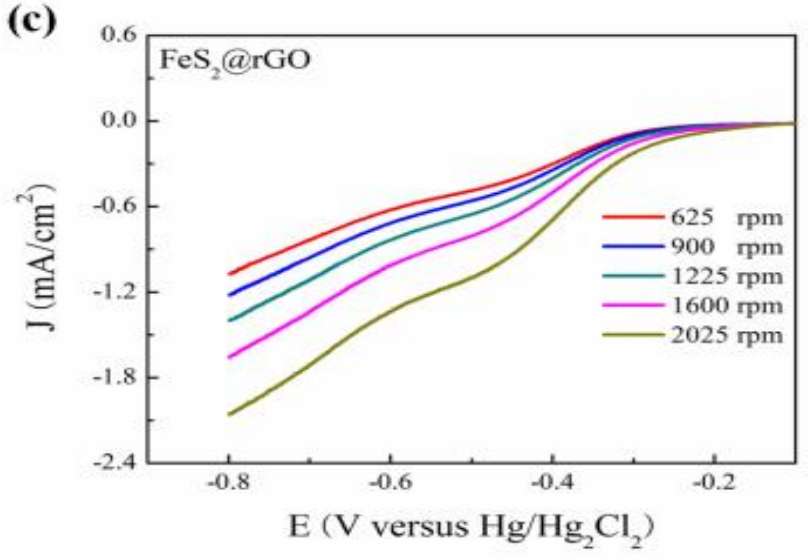

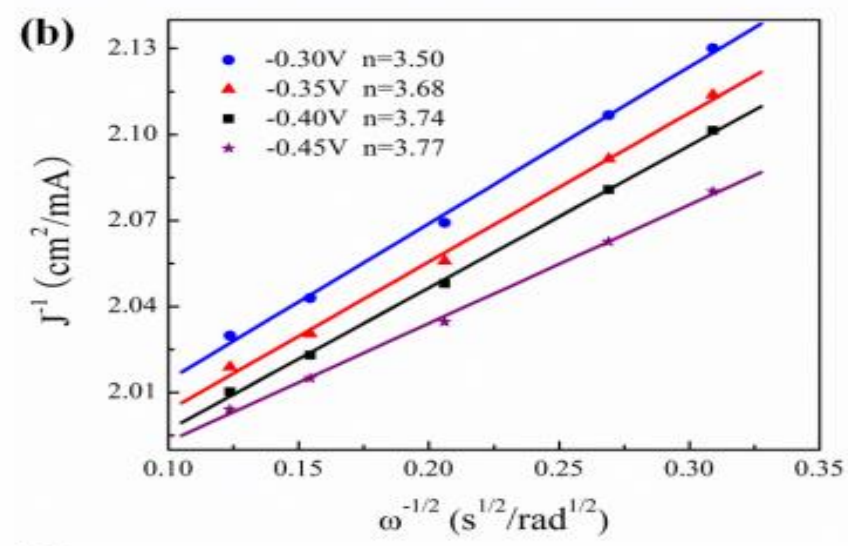

(d)

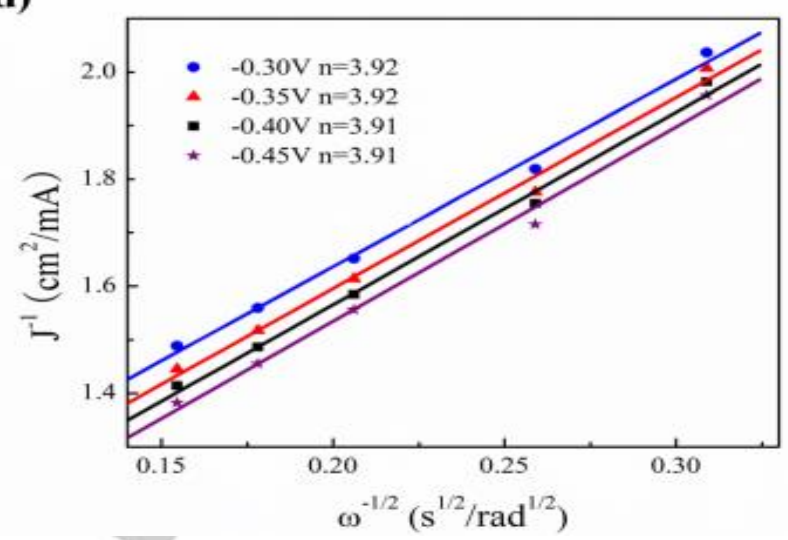

Figure 6. RDE tests and corresponding K-L lines of FeS@rGO (a) and (b), and FeS ${ }_{2} @ r G O$ (c) and (d) in oxygen saturated 0.1 M KOH at different rotating speeds with the sweeping rate of $0.005 \mathrm{~V} \mathrm{~s}^{-1}$.

(a)

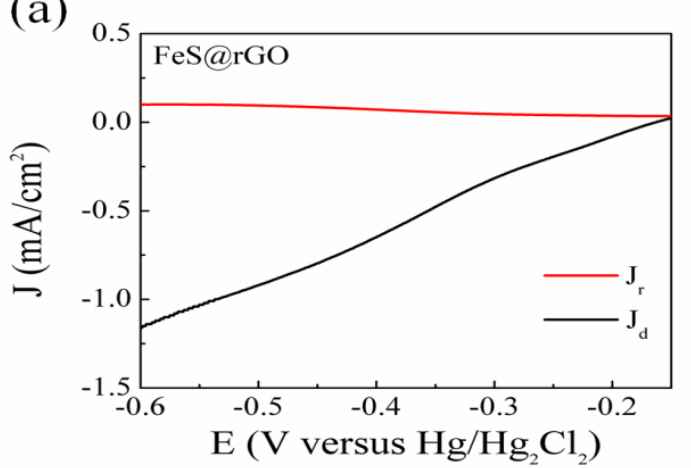

(c)

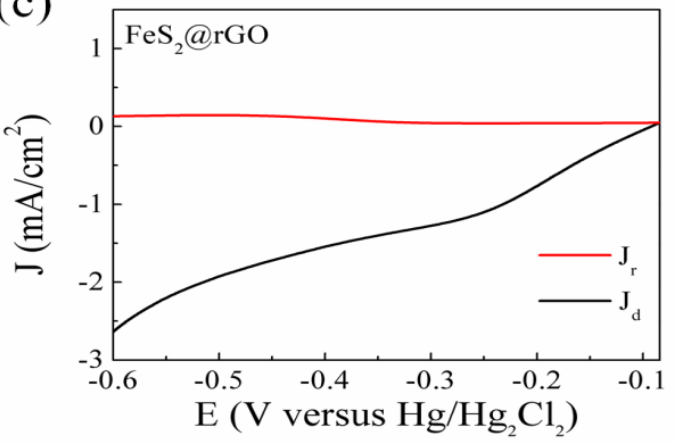

(b)

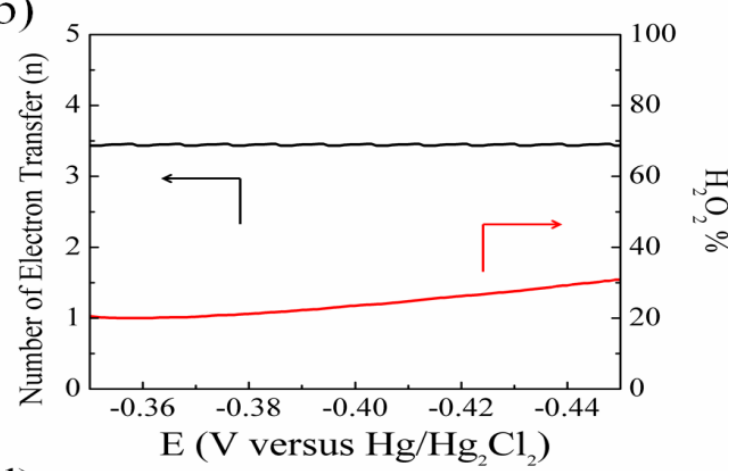

(d)

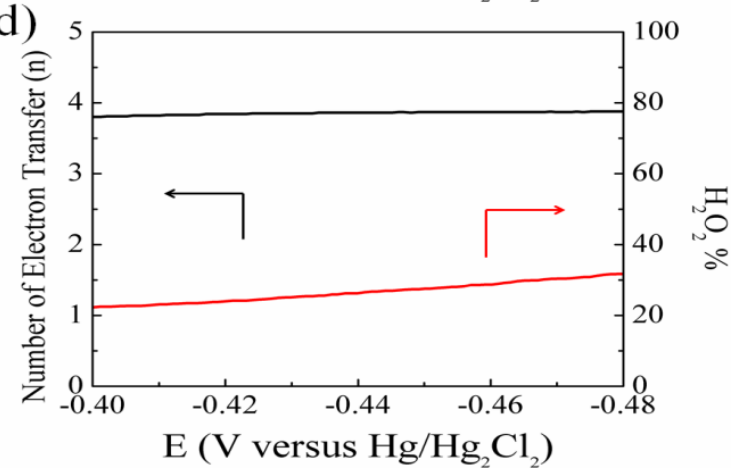


Figure 7. RRDE test results of (a) FeS@rGO and (c) FeS $\mathrm{F}_{2} @ r G O$ at 1600 rpm, and the corresponding electron transfer numbers $(n)$ and the percentage of $\mathrm{H}_{2} \mathrm{O}_{2} \%$ of FeS@rGO (b) and FeS2@rGO (d).

Based on the RDE tests, the electron transfer number (n) can be calculated according to the Koutechy-Levich (K-L) equation (2): ${ }^{[30]}$

$$
\frac{1}{J}=\frac{1}{J_{L}}+\frac{1}{J_{K}}=\frac{1}{B \omega^{-1 / 2}}+\frac{1}{J_{K}}
$$

where $J$ is the measured current intensity, $J_{K}$ is the kinetic current intensity, $J_{L}$ is the diffusion limiting current intensity, and $\omega$ is the electrode rotating speed. $B$ is the slope of the $\mathrm{K}-\mathrm{L}$ line, as defined in the Koutechy-Levich equation, which can be written as Equation (3): [31]

$$
B=0.62 n F C_{0}\left(D_{0}\right)^{2 / 3} v^{-1 / 6}
$$

where $n$ is the electron transfer number, $F$ is the Faraday constant: $96,485 \mathrm{C} \mathrm{mol}^{-1}$, $D_{0}\left(1.9 \times 10^{-5} \mathrm{~cm}^{2} \mathrm{~S}^{-1}\right)$ is the diffusion coefficient of $\mathrm{O}_{2}$ in the $0.1 \mathrm{M} \mathrm{KOH}$ electrolyte, $u$ $\left(0.01 \mathrm{~cm}^{2} \mathrm{~s}^{-1}\right)$ is the kinetic viscosity, and $C_{0}\left(1.2 \times 10^{-6} \mathrm{~mol}\right.$ $\mathrm{cm}^{-3}$ ) is the bulk concentration of $\mathrm{O}_{2}$ in the electrolyte. The constant 0.62 is adopted when the rotating speed $\omega$ is expressed in $\mathrm{rad} / \mathrm{s}$. The electron transfer numbers are calculated from the slopes of the K-L plots, and the results are shown in Figure 6 (FeS@rGO and FeS $\left._{2} @ r G O\right)$ and Figure $\mathrm{S} 12$ ( $\mathrm{FeS}$ and $\mathrm{FeS}_{2}$ ). The obtained electron transfer numbers of FeS, FeS@rGO, FeS 2 , and FeS ${ }_{2} @ r G O$ are 3.41, 3.67, 3.69 and 3.92, respectively. Based on the results, it can be deduced that the ORR mainly happen through 4-electron pathway. Only a small amount of oxygen is reduced through 2-electron pathway. The 4-electron and 2-electron ORR pathways are as follows: ${ }^{[32]}$

4-electron pathway: $\mathrm{O}_{2}+2 \mathrm{H}_{2} \mathrm{O}+4 e^{-} \rightarrow 4 \mathrm{OH}^{-}$

(4)

2-electron pathway: $\mathrm{O}_{2}+2 \mathrm{H}_{2} \mathrm{O}+2 e^{-} \rightarrow 2 \mathrm{OH}^{-}+\mathrm{H}_{2} \mathrm{O}_{2}$ (5)

$$
\mathrm{H}_{2} \mathrm{O}_{2}+2 e^{-} \rightarrow 2 \mathrm{OH}^{-}
$$

Similarly, the calculated electron transfer number $(n)$ and the percentage of generated hydrogen peroxide were further evaluated by using rotating ring disk electrode (RRDE) tests. Figure 7 shows the current intensity of disc electrode and collection ring of $\mathrm{Pt}$. Based on the RRDE tests, the electron transfer number and the percentage of $\mathrm{H}_{2} \mathrm{O}_{2}$ were calculated according to the Eqs. (7) and (8)::[33]

$$
\begin{aligned}
& n=\frac{4 \times I_{d}}{I_{d}+I_{r} / N} \\
& H_{2} O_{2}=200 \times \frac{I_{r} / N}{I_{d}+I_{r} / N}
\end{aligned}
$$

where $I_{d}$ is the disk current, $I_{r}$ is the ring current, and $N$ is the geometrical current collection coefficient of $\mathrm{Pt}$ in the RRDE (0.39). Figure $7 \mathrm{c}$ clearly shows that the current intensity of $\mathrm{FeS}_{2} @ \mathrm{rGO}$ and FeS@rGO is $2.7 \mathrm{~mA} \mathrm{~cm} \mathrm{~cm}^{-2}$ and $1.1 \mathrm{~mA} \mathrm{~cm}{ }^{-2}$, respectively. As shown in Figure 7 and Figure S13, the calculated electron transfer number for FeS, FeS@rGO, $\mathrm{FeS}_{2}$, and $\mathrm{FeS}_{2} @ \mathrm{rGO}$ are 3.48, 3.85, 3.72 and 3.92, respectively. The results are consistent with the RDE test results. The obtained percentages of $\mathrm{H}_{2} \mathrm{O}_{2}$ are $32.5 \%, 24.8 \%$, $33.4 \%$ and $15.8 \%$, respectively. Based on the RDE and RRDE tests, it could be deduced that the 4-electron and 2electron pathways of the ORR coexisted on the electrode. The occurrence of the 2-electron reaction is also inevitable in theory. ${ }^{[34]}$ The outer-sphere electron transfer mechanism in alkaline media is likely to be responsible for the unwanted 2-electron hydrogen peroxide intermediate. ${ }^{[35]}$ The innersphere electrocatalytic process is the direct cause of the 4electron pathway.

A Faradaic Efficiency determination and post catalysis XPS analysis were test, which in order to exploring the stability of all the catalysts in the $\mathrm{O}_{2}$-saturated $0.1 \mathrm{M} \mathrm{KOH}$ electrolyte. In addition, the RRDE was tested at a ring potential at $-0.4 \mathrm{~V}$ to gain insight into the reaction mechanism.

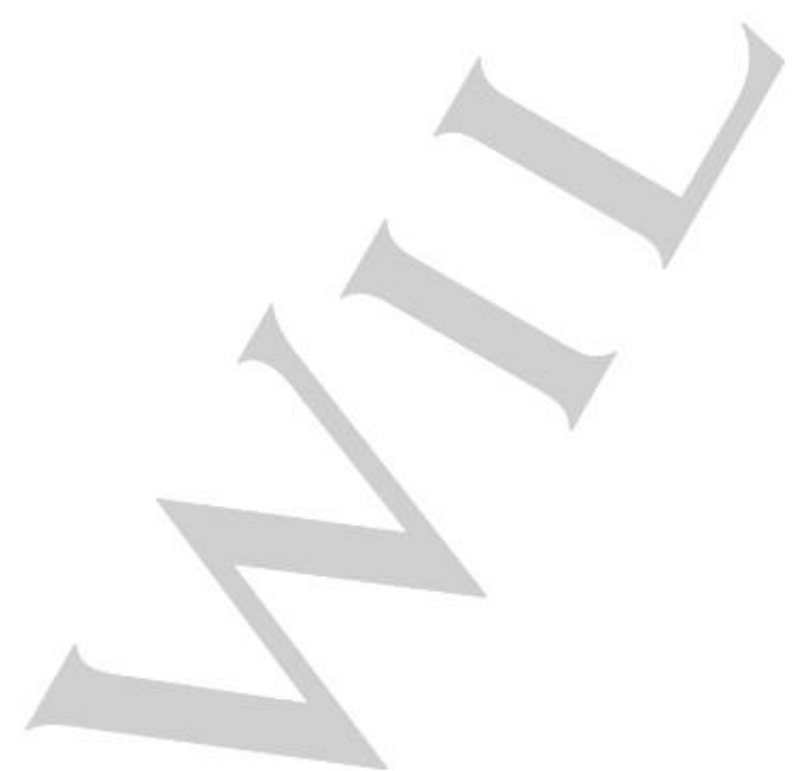



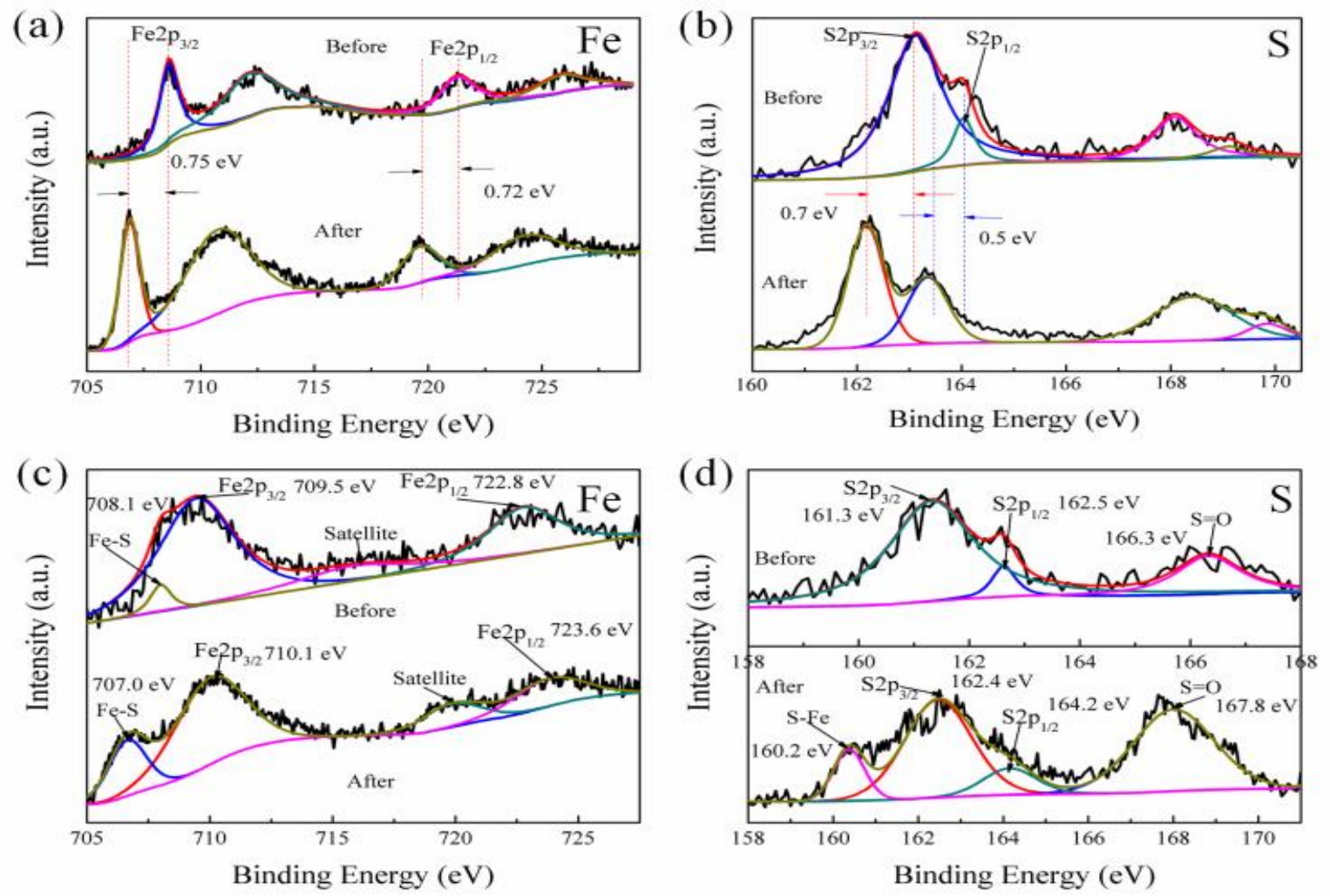

Figure 8. Post catalysis XPS analysis of Fe (a) and S (b) for FeS $2 @ r G O, F e(c)$ and S (d) for FeS@rGO.

It could be found that the collected ring current is much lower than disk current, indicating that the less intermediate product $\left(\mathrm{H}_{2} \mathrm{O}_{2}\right)$ and the approximately four-electron transfer pathway for ORR. The Faradaic efficiency was calculated by test of the continuous OER (disk electrode)-ORR (ring electrode) process using the RRDE. The Faradaic efficiency was calculated by the equation followed:

$$
\varepsilon=I_{\mathrm{r}} /\left(I_{d}{ }^{*} \mathrm{~N}\right)
$$

Where $I_{r}$ is the collected ring current of $45 \mu \mathrm{A}, I_{d}$ is the disk current, $N$ is the current collection efficiency $(0.39$ in this study). After calculation, the Faradaic efficiency of FeS, FeS@rGO, FeS 2 , and $\mathrm{FeS}_{2} @ \mathrm{rGO}$ is $73.2 \%, 83.5 \%, 77.1 \%$ and $87.9 \%$, respectively. Due to the generation of hydrogen peroxide, the Faraday efficiency will be affected by it and will be reduced to some extent. The occurrence of side reactions during the reaction has certain negative effects on the oxygen reduction reaction. For example, hydrogen evolution or the generation of hydrogen peroxide is the cause of the decrease in Faraday efficiency. Faraday's efficiency is one of the criteria for judging material stability. The stability of the material should also be combined with other test results, such as the i-t curve. The Faraday efficiency of FeS2@RGO is the highest among the four catalyst materials, which is also consistent with the measured i-t curve, which proves the stability of the prepared FeS2@RGO material. Figure 8 showed the Post catalysis XPS analysis of $\mathrm{FeS}_{2} @ r G O$ and FeS@rGO. It was clearly showed that the binding energy of the Fe and $\mathrm{S}$ of $\mathrm{FeS}_{2} @ r G O$ and FeS@rGO had a small shift after the reaction, which meant that no chemical bond changes happened during the reaction. The post analysis XPS of the catalyst also proved the long-term running stability of $\mathrm{FeS}_{2} @ r G O$ and FeS@rGO.The similar results of $\mathrm{FeS}_{2}$ and $\mathrm{FeS}$ were also obtained the results are showed in the Figure S14. The results of Faradaic Efficiency determination and post catalysis XPS analysis were consistent with the long-time running stability test, which certified the high long-time running stability of the catalysts.

Based on the above results, it can be seen that the hybrid of FeS@rGO and FeS $\mathrm{S}_{2} @ r G O$ show better catalytic performance for ORR than the pristine $\mathrm{FeS}$ and $\mathrm{FeS}_{2}$. This can be attributed to the synergistic effects between $\mathrm{rGO}$ and $\mathrm{FeS}_{2} / \mathrm{FeS}$, which alter the surface electron configuration for oxygen adsorption/activation and provide networks for efficient electron transfer. ${ }^{[36]}$ On the other hand, among all the catalysts, the $\mathrm{FeS}_{2} @ r \mathrm{rGO}$ shows the highest catalytic efficiency and lowest polarization for ORR. The shortened $\mathrm{Fe}-\mathrm{S}$ bond length of $\mathrm{FeS}_{2}$ favors the low-spin $(S=0)$ ground state of electrons compared with the high-spin FeS, ${ }^{[37]}$ which is benefit to the happening of the ORR. Impressively, the peak current intensity and the onset potential of FeS ${ }_{2} @ r G O$ are quite close to that of the super $\mathrm{Pt} / \mathrm{C}$ catalyst. The longtime running stability of $\mathrm{FeS}_{2} @ r G O$ is even better than that of $\mathrm{Pt} / \mathrm{C}$ catalyst. ${ }^{[38]}$ It could be forecasted that the $\mathrm{FeS}_{2} @ \mathrm{rGO}$ has great potential to be a high performance substitute for the precious metal-based catalysts for ORR. 


\section{Conclusions}

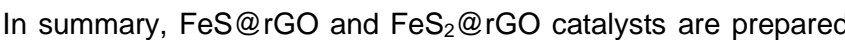
via a facile method, and their electrocatalytic performances for ORR are reported. Results show that the FeS@rGO and $\mathrm{FeS}_{2} @ r G O$ catalysts show much better catalytic activity for ORR than the pristine $\mathrm{FeS}$ or $\mathrm{FeS}_{2}$, which should be attributed to the synergistic effect between rGO and metal sulfides. Remarkably, the onset potentials of FeS ${ }_{2} @ r G O$ catalyzed ORR is close to that of $\mathrm{Pt} / \mathrm{C}$ catalyst. The long-time running stability of $\mathrm{FeS}_{2} @ \mathrm{rGO}$ surpasses that of $\mathrm{Pt} / \mathrm{C}$ catalyst. Based on the research, it can be concluded that the low cost, high performance Fe-based sulphide based catalysts have great potential to be substitute for the precious-based catalysts for ORR. This work provides some new insights for further design of high efficient non-noble metal based electrocatalysts for ORR through constructing novel nanostructured graphene based composites.

\section{Supporting Information Summary}

Experimental details including chemical reagents, synthesis procedure of the FeS, FeS@rGO, FeS ${ }_{2}$ and FeS ${ }_{2} @ r G O$, detailed characterisation techniques, electrochemical measurements, materals characterisation data including XPS survey spectra, SEM images, EDS spectrum, and electrochemical measurements of FeS, FeS@rGO, FeS ${ }_{2}$ and $F_{e} S_{2} @ r G O$.

\section{Acknowledgements}

This work was financially supported by the Science Development Project of Shandong Province (No. 2017GGX40115, 2016GGX102038) and the National Natural Science Foundation of China (No. 21407060). The authors would like to thank the shiyanjia lab for the supporting of XPS analysis. The authors also would like to thank Dr. Tania Silver at the University of Wollongong for English editing.

Keywords: Catalysis; Electrocatalysts; $\mathrm{FeS} ; \mathrm{FeS}_{2}$; Oxygen reduction reaction; Reduced graphene oxide

[1] a) B. C. H. Steele, J. Mater. Sci. 2001, 35, 1053-1068; b) K. Ahmed, K. Föger, Ind. Eng. Chem. Res. 2010, 49, 7239-56; c)X. Zhou, J. Qiao, L. Yang, J. Zhang, J. Adv. Energy Mater. 2014, 4, 1301523; d) S. C. Singhal, Solid State lonics 2000, 135, 305-313; e) Y.J. Wang, J. Qiao, R. Baker, J. Zhang, Chem. Soc. Rev. 2013, 42, 5768-5787; f) B. C. H. Steele, Nature 2001, 414, 345-352.

[2] a) L. Gan, Heggen, M. Heggen, O'Malley, R. O'Malley, B. Theobald, P. Strasser, Nano Lett. 2013, 13, 1131-1138; b) M. S. Çögenli, S. Mukerjee, A. B. Yurtcan, Fuel Cells 2015, 15, 288-297; c) E. P. Murray, T. Tsai, S A. Barnett, Nature 1999, 400, 649; d) F. Cheng, J. Chen, Chem. Soc. Rev. 2012, 41, 2172-2192.

[3] a) E. Gülzow, Fuel Cells 2004, 4, 251-255; b) G. Merle, M. Wessling, K. Nijmeijer, J. Membr. Sci. 2011, 377, 1-35.

[4] a) Y. Sun, C. Li, G. Shi, J. Mater. Chem. 2012, 22, 12810; b) M. Chen, J. Liu, W. Zhou, J. Lin, Z. Shen, Sci. Rep. 2015, 5, 10389.
[5] a) L. Lai, J. R. Potts, D. Zhan, L. Wang, C. K. Poh, C. Tang, H. Gong, Z Shen, J. Lin, R. S. Ruoff, Energ Environ. Sci. 2012, 5, 7936-7942; b) Z.H Sheng, H.L. Gao, W.-J. Bao, F.B. Wang, X.H. Xia, J. Mater. Chem. 2012, 22, 390-395; c) K. Gong, F. Du, Z. Xia, M. Durstock, L. Dai, Science 2009, 323, 760-764

[6] a) Y. Feng, N. Alonso-Vante, Phys. status solidi B. 2008, 245, 1792-1806 b) M. S. Faber, M. A. Lukowski, Q. Ding, N. S. Kaiser, S. Jin, J. Phys. Chem. C 2014, 118, 21347-21356; c) M.R. Gao, J. Jiang, S.H. Yu, Small 2012, 8, 13-27.

[7] Y. C. Wang, Y. J. Lai, L. Song, Z. Y. Zhou, J. G. Liu, Q. Wang, X. D. Yang, C. Chen, W. Shi, Y.P. Zheng, M. Rauf, S.G. Sun, Angew. Chem. Int. Ed. 2015, 54, 9907-9910.

[8] F. Rodríguez-Reinoso, Carbon 1998, 36, 159-175

[9] J. Lee, J. Kim, T. Hyeon, Adv. Mater. 2006, 18, 2073-2094.

[10] E. Frackowiak, Phys. Chem. Chem. Phys. 2007, 9, 1774-85.

[11] M. S. Dresselhaus, P. Avouris, Introduction to carbon materials research. Vol. 80 (Eds.: M. S. Dresselhaus, G. Dresselhaus, P. Avouris) Springer, Berlin and Heidelberg, 2001, pp. 1-9.

[12] a) T. Huang, S. Mao, G. Zhou, Z. Wen, X. Huang, S. Ci, J. Chen, Nanoscale 2014, 6, 9608-9613; b) T. Huang, S. Mao, H. Pu, Z. Wen, X Huang, S. Ci, J. Chen, J. Mater. Chem. A 2013, 1, 13404-13410.

[13] a) Y. Hou, T. Huang, Z. Wen, S. Mao, S. Cui, J. Chen, Adv. Energy. Mater. 2014, 4, 1400337; b) X. Yuan, H.D. Sha, X.L. Ding, H.C. Kong, H. Lin, W. Wen, T. Huang, Z. Guo, Z.F. Ma, Y. Yang, Int. J. Hydrogen Energy 2014, 39, 15937-15947.

[14] a) M. D. Meganathan, S. Mao, T. Huang, G. Sun, J. Mater. Chem. A. 2017, 5, 2972-2980; b) J. Xu, P. Gao, T.S. Zhao, Energ. Environ. Sci 2012, 5, 5333-5339; c) F. Cheng, T. Zhang, Y. Zhang, J. Du, X. Han, J. Chen, Angew. Chem. Int. Ed. 2013, 52, 2474-2477; d) Y. Zhao, K. Kamiya, K. Hashimoto, S. Nakanishi, J. Phys. Chem. C 2015, 119, 25832588.

[15] S. Kong, Z. Jin, H. Liu, Y. Wang, J. Phys. Chem. C 2014, 118, 2535525364.

[16] Jr. Hummers, S. W, R. E. Offeman, J. Am. Chem. Soc. 1958, 80, 1339 1339.

[17] S. Park, J. An, J. R. Potts, A. Velamakanni, S. Murali, R. S. Ruoff, Carbon 2011, 49, 3019-3023.

[18] D. Yan, Y. Li, J. Huo, R. Chen, L. Dai, S. Wang, Adv. Mater 2017,1606459.

[19] a) K. Chang, W. Chen, ACS Nano 2011, 5, 4720-4728; b) D. Long, W Li, L. Ling, J. Miyawaki, I. Mochida, S.-H. Yoon, Langmuir 2010, 26, 16096-16102

[20] L. Xu, Y. Hu, H. Zhang, H. Jiang, C. Li, ACS Sustain. Chem. Eng. 2016, 4, 4251-4255

[21] a) J. Zhang, H. Yang, G. Shen, P. Cheng, J. Zhang, S. Guo, Chem Commun. 2010, 46, 1112-1114; b) Y. Li, W. Li, T. Ke, P. Zhang, X. Ren L. Deng, Electrochem. Commun. 2016, 69, 68-71.

[22] M. Nath, A. Choudhury, A. Kundu, C. N. R. Rao, Adv. Mater. 2003, 15 2098-2101.

[23] J. Liu, L. Wan, M. Zhang, K. Jiang, K. Song, J. Wang, T. Ikeda, L. Jiang Adv. Funct. Mater. 2017, 27, 1605221.

[24] M. Shen, C. Ruan, Y. Chen, C. Jiang, K. Ai, L. Lu, ACS Appl. Mater Interfaces 2015, 7, 1207-1218.

[25] D. Susac, L. Zhu, M. Teo, A. Sode, K. C. Wong, P. C. Wong, R. R Parsons, D. Bizzotto, K. A. R. Mitchell, S. A. Campbell, J. Phys. Chem C 2007, 111, 18715-18723.

[26] X. Sun, Y. Zhang, P. Song, J. Pan, L. Zhuang, W. Xu, W. Xing, ACS Catal. 2013, 3, 1726-1729.

[27] Y. Zhu, B. Zhang, X. Liu, D.W. Wang, D. Su, Angew. Chem. 2014, 53, 10673-10677.

[28] K. N. Kudin, B. Ozbas, H. C. Schniepp, R. K. Prud'Homme, I. Aksay, R. Car, Nano Lett. 2008, 8, 36-41.

[29] a) J. Liang, Y. Jiao, M. Jaroniec, S. Qiao, Angew. Chem. 2012, 51, 11496-11500; b) J. Yu, X. Gao, G. Chen, X. Yuan, Int. J. Hydrogen Energy 2016, 41, 4150-4158.

[30] H. Yang, S. Zhang, L. Han, Z. Zhang, Z. Xue, J. Gao, Y. Li, C. Huang, Y Yi, H. Liu, Y. Li, ACS Appl. Mater. Interfaces 2016, 8, 5366-75. 
[31] Z. Li, B. Li, Z. Liu, Z. Liu, D. Li, RSC Adv. 2015, 5, 106245-106251.

[32] a) E. Peled, J. Electrochem. Soc. 1979, 126, 2047-2051; b) P. Velasquez, D. Leinen, J. Pascual, J. R. Ramos-Barrado, P. Grez, H. Gomez, R. Schrebler, R. Del. Río, R. Cordova, J. Phys. Chem. B 2005, 109, 4977 4988; c) C. Wen, X. Gao, T. Huang, X. Wu, L. Xu, J. Yu, H. Zhang, Z. Zhang, J. Han, H. Ren, Int. J. Hydrogen Energy 2016, 41, 11099-11107.

[33] X. Wu, X. Gao, L. Xu, T. Huang, J. Yu, C. Wen, Z. Chen, J. Han, Int. J. Hydrogen Energy 2016, 41, 16087-16093.

[34] J. Jiang, S. Lu, H. Gao, X. Zhang, H.-Q. Yu, Nano Energy 2016, 27, 526 534.

[35] W. Ai, Z. Luo, J. Jiang, J. Zhu, Z. Du, Z. Fan, L. Xie, H. Zhang, W. Huang, T. Yu, Adv. Mater. 2014, 26, 6186-6192.

[36] a) J.M. You, M. S. Ahmed, H. Han, J. e. Choe, Z. Üstündağ, S. Jeon, J. Power Sources 2015, 275, 73-79; b) N. Ramaswamy, S. Mukerjee, J. Phys. Chem. C 2011, 115, 18015-18026; c) Y. Zheng, Y. Jiao, J. Chen, J. Liu, J. Liang, A. Du, W. Zhang, Z. Zhu, S. C. Smith, M. Jaroniec, G. Lu, S. Qiao, J. Am. Chem. Soc. 2011, 133, 20116-20119.

[37] A. Fujimori, K. Mamiya. T. Mizokawa, T. Mayadai, T. Sekiguchi, H. Takahashi, N. Mori. S. Suga. Phys. Rev. B 1996, 54, 16329.

[38] S. Bag, B. Mondal, A. K. Das, C. R. Raj, Electrochim Acta 2015, 163, $16-$ 23. 


\section{Entry for the Table of Contents}

\section{FULL PAPER}

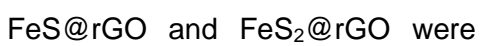
synthesized in a simple way. These compounds exhibited outstanding electrocatalysis activity and excellent electrochemical durability for oxygen reduction reaction (ORR) in alkaline media.

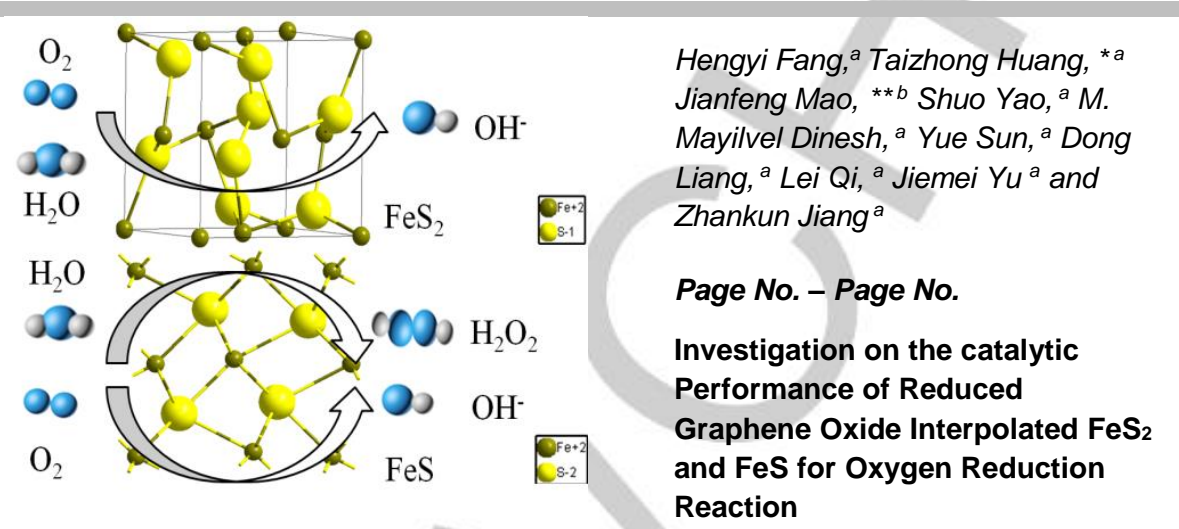

